\title{
Establishment of combined immuno-chemotherapy with systemically administered gemcitabine and intra-portal administration of interleukin-2 in murine models of liver metastases of pancreatic cancer
}

\author{
YASUHIRO ITO, KOICHI AIURA, MASAKAZU UEDA, MASAKI KITAJIMA and YUKO KITAGAWA
}

Department of Surgery, Keio University School of Medicine, Tokyo, Japan

Received February 9, 2008; Accepted March 28, 2008

\begin{abstract}
Despite attempts to use multiple drug combinations that include gemcitabine (GEM), there is very little evidence that these combination regimens are superior to the single use of this agent. We therefore investigated the suppressive effect of the combination of systemically administered GEM and locally administered interleukin-2 (IL-2) on liver metastasis in pancreatic cancer. Tumor-bearing mice were randomly divided into four groups: a control group, an IL-2 intrasplenic (is) administration group, a GEM intraperitoneal (ip) administration group, and a GEM ip+IL-2 is group. Liver weight, liver metastases, and tumor diameter (as assessed by the Winn assay) were compared among groups. Liver weight was significantly lower in the GEM+IL-2 group than in the control and IL-2 groups. The number of liver metastases was significantly reduced in the GEM+IL-2 group compared with all other groups. Splenocyte production of interferon- $\gamma$ increased significantly in the GEM+IL-2 group after stimulation with Concanavalin A. Furthermore, tumor diameter was significantly reduced in the GEM+IL-2 group in the Winn assay when compared to that of the control group. These findings suggest that a combined regimen of GEM and portally administrated IL-2 might prevent liver metastasis in pancreatic cancer patients more effectively than current approaches and could prove useful as a postsurgical adjuvant therapeutic.
\end{abstract}

\section{Introduction}

Pancreatic cancer has a poor prognosis, even when resectable, because of its high frequency of recurrence, including liver

Correspondence to: Dr Koichi Aiura, Department of Surgery, Keio University School of Medicine, 35 Shinanomachi, Shinjuku-ku, Tokyo 160-8582, Japan

E-mail: aiurako@sc.itc.keio.ac.jp

Key words: pancreatic cancer, immuno-chemotherapy, interleukin-2, gemcitabine, adjuvant therapy metastasis after surgical resection. In recent years, the nucleoside analog gemcitabine (GEM) has attracted considerable attention as a chemotherapeutic for non-resectable progressive pancreatic cancer; however, the efficacy rate remains low at $5-18 \%$ (1-4). Despite attempts to use multiple drug therapies that include GEM, there is little to support the premise that GEM-containing combination regimens are superior to sole use of this agent (1-8; Heinemann et al, Proc ASCO 22: abs. $1003,2003)$. In addition, the effect of adjuvant chemotherapy with GEM after surgical resection has not been established (9). As a result, there are few effective approaches to the treatment of liver metastasis in pancreatic cancer, even after surgery, and there is an urgent need for the development of new therapeutic modalities.

Barriers to the development of more effective agents include decreased host immunological competence associated with administration of anticancer agents. However, studies that have evaluated the effect of multiple drug combination therapy on liver metastases in hepatocellular and colorectal carcinomas have found that the combined use of chemotherapy and immunotherapy [e.g., fluorouracil (5-FU) and interferon- $\alpha$ (IFN- $\alpha$ ), 5-FU and interleukin-2 (IL-2), etc.] provides better therapeutic outcomes than treatments with a single anticancer agent $(10,11)$. GEM, the first-line treatment for unresectable pancreatic cancer, induces apoptosis and exerts anti-tumor effects (12), and creates a beneficial situation wherein antigen presentation potentiates anti-tumor immunity. In solid carcinomas of the digestive tract, such as pancreatic cancer, it is highly probable that cancer cells, which cannot be excluded from the immune system, are selectively augmented. Since such carcinomas are essentially considered to have low immunogenicity, anti-tumor immunity can be further activated, and the tumor eliminated, if a cytokine that strongly activates the immune system is administered simultaneously with GEM.

IL-2 is a potential candidate for cytokine treatment due to its activation of anti-tumor immunity in solid low-antigenicity carcinomas of the digestive organs. However, singleagent IL-2 is predicted to have limitations (13). When IL-2 is administered systemically, its concentrations at local tumor sites possibly remain suboptimal, thereby limiting the antitumor effect. Furthermore, systemic administration leads to side-effects, i.e., influenza-like symptoms and capillary leak 
syndrome (14-17). Thus, local administration of a cytokine is considered an efficient means of attaining adequate cytokine concentrations at local tumor sites and of minimizing toxic side-effects. The liver is an immunocompetent organ (18), and it is highly probable that local administration of IL-2 for the prevention or treatment of liver metastasis more efficiently activates local immunocompetent cells and decreases systemic side-effects. It is also highly probable that tumor antigens are released from tumor cells in which apoptosis has been induced by GEM administration, and that their incorporation by antigen-presenting cells is increased, thereby enhancing the differential derivation of cytotoxic T lymphocytes (CTL) by locally administered IL- 2 .

The effect of combination therapy, primarily as an adjuvant treatment strategy, on systemically administered GEM and locally administered IL-2 on liver metastasis, was investigated using a metastatic mouse model of pancreatic cancer. A decrease in the development of liver metastasis in this murine model of highly refractory pancreatic cancer was used as a measure of the suppressive effect of the combined chemotherapy and immunotherapy regimen.

\section{Materials and methods}

Pancreatic cancer cell strain. The murine pancreatic cancer tumor cell strain used was PAN02 (ductal adenocarcinoma, pancreatic cancer derived from C57BL/6J mice), which was provided by the National Cancer Institute-Frederick Cancer Research and Development Center. Standard medium was prepared by mixing $10 \%$ fetal calf serum with RPMI-1640 (Gibco, Gaithersburg, MD, USA) containing $100 \mathrm{IU} / \mathrm{ml}$ penicillin $\mathrm{G}, 100 \mu \mathrm{g} / \mathrm{ml}$ streptomycin, and $0.25 \mu \mathrm{g} / \mathrm{ml}$ amphotericin $\mathrm{B}$. The cells were cultured at $37^{\circ} \mathrm{C}$ in $5 \% \mathrm{CO}_{2}$. The sensitivity of GEM as an anticancer substance was evaluated at $72 \mathrm{~h}$ by MTT assay. The MTT assay conformed to the modification of the method (19-21) reported by Mosmann (22) i.e., the 3-(4,5-dimethylthiazol-2 yl)-2,5-diphenyl-2H tetrazolium bromide (MTT) method. A suspension of $5 \times 10^{4}$ cells per $\mathrm{ml}$ of standard medium was prepared, and $200 \mu \mathrm{l}$ of the suspension per well $\left(10^{4}\right.$ cells/well $)$ were dispersed on a 96-well microplate. The plate was pre-incubated for $24 \mathrm{~h}$ at $37^{\circ} \mathrm{C}$ in an environment of $5 \% \mathrm{CO}_{2}$. After pre-incubation, the final concentration was set at that $(10-100 \mathrm{ng} / \mathrm{ml})$ for GEM. After continuous contact for $72 \mathrm{~h}$, the MTT assay was performed; the MTT reagent was added after culture, and the mixture was allowed to react for $4 \mathrm{~h}$ at $37^{\circ} \mathrm{C}$. The MTT reagent was adjusted by mixing 3-(4,5-dimethylthiazol-2 yl)-2,5diphenyl-2H tetrazolium bromide (Sigma, St. Louis, MO, USA) with $0.1 \mathrm{~mol} / 1$ sodium succinate at a proportion of $1: 1$. Dimethyl sulfoxide was also added, and the MTT formazan salt, which was formed by shaking the microplate on the mixer (Model 250, Sonifier, Branson, MO, USA) for several min, was dissolved, thereby allowing emission. Absorbance was determined at 570-630 nm with an EAR easy reader (SLT-Lab Instruments, Salzburg, Austria). The wells without MTT reagent or succinic acid were used as 'blanks', and the rate of tumor growth suppression was obtained from the formula: [1-(mean absorbance in the treatment group - mean absorbance for blank)/(mean absorbance in the control group mean absorbance for blank)] x $100(\%)$. The mean rate for 4 wells was calculated. Curves were prepared from drug concentrations and the rate of tumor growth suppression, and a sample regression equation $(y=a+b x)$ was introduced to correlate the drug concentration ( $\mathrm{x}$ ) and the rate of growth suppression $(\mathrm{y})$. The concentration at which tumor growth was suppressed in $50 \%$ of the growing cells $\left(\mathrm{IC}_{50}\right)$ was obtained from the formula: $\operatorname{IC}_{50}=(50-a) / b$.

The rate of tumor growth suppression for PAN02 was $5.0 \%$ with GEM (freeze-dried product supplied by Eli Lilly and Co., Indianapolis, IN, USA) at $10 \mathrm{ng} / \mathrm{ml}$. The rates were $38.6,57.7$, and $85.1 \%$ at 50,80 , and $100 \mathrm{ng} / \mathrm{ml}$, respectively, showing the anti-tumor effect of GEM to be dependent on the concentration (Fig. 1).

Animals. All uses of experimental animals conformed to the experimental guidelines established by the Keio University School of Medicine. Six-week-old C57BL/6J female mice, each weighing 20-22 g, were purchased from the Saitama Experimental Animal Center, and used in the present study. All the mice were housed in a room with an illumination cycle of 8:00-20:00 and were allowed water ad libitum for 1 week before use at our Experimental Animal Center.

Preparation of liver metastasis of pancreatic cancer models. Anesthesia was administered by intraperitoneal injection of $0.08 \mathrm{mg}$ of pentobarbital (Dainippon Pharmaceutical Co., Ltd., Osaka, Japan) per gram of body weight. After intraperitoneal injection of pentobarbital, an incision of $\sim 2 \mathrm{~cm}$ was made aseptically on the right hypochondrium for laparotomy. The portal vein was identified and exposed. PAN02 cells suspended in PBS were injected in a volume of $50 \mu 1$ into the portal vein using a $250-\mu 1$ syringe with a $30-\mathrm{G}$ needle. After confirmation of the absence of hemorrhage from the injection site, the abdominal incision was closed with metallic clips (Autoclip; Clay Adams, Parsippany, NJ, USA). The cell count injected was determined in a preliminary experiment. The survival rate 30 days after PAN02 cell transplantation was $100 \%$ with: Group A, $5 \times 10^{4}$ cells $(n=5)$; Group B, $1 \times 10^{5}$ cells $(\mathrm{n}=5)$; Group C, $2 \times 10^{5}$ cells $(\mathrm{n}=5)$; and Group D, $5 \times 10^{5}$ cells $(n=7)$. The rate with Group E, $1 \times 10^{6}$ cells $(n=7)$, was $71.4 \%$. The rates 60 days after transplantation in Groups A, B, C, D and $\mathrm{E}$ were 80, 60, 20,0 and 0\%, respectively (Fig. 2). When $5 \times 10^{5}$ cells of Group D were injected into the portal vein, the liver metastasis showed diffuse proliferation with a strong tendency toward fusion 2 weeks later, suggesting the metastatic disease in this model to be stable, making it an appropriate liver metastasis model for the present study.

Preparation of murine models of IL-2 injection into the portal vein. IL-2 was used with the aim of increasing the regional tumor immunity of the liver, and it was injected repeatedly into the portal vein. The IL-2 was a freeze-dried product obtained from Shionogi \& Co., Ltd., Osaka, Japan. The method for repeated injection into the portal vein was essentially modified from the previously reported method (23), i.e., a small incision of $\sim 1 \mathrm{~cm}$ was made on the left dorsal side, and the spleen was raised outside the peritoneum. It was moved to the space between the peritoneum and the skin, and fixed. IL-2 dissolved in PBS was injected in a volume of $10 \mu \mathrm{l}$ by means of a $100-\mu 1$ syringe with a $30-\mathrm{G}$ needle into the spleen, 


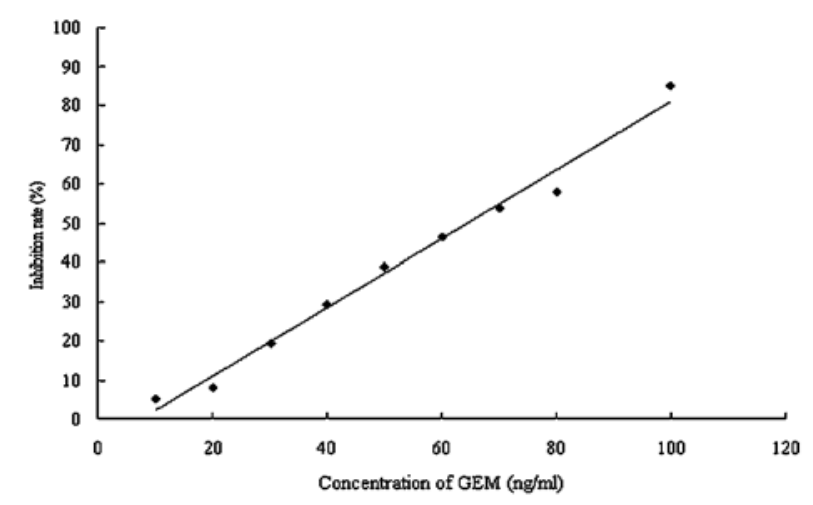

Figure 1. In vitro anti-tumor effects of GEM on a tumor cell strain of murine pancreatic cancer (PAN02) (MTT assay). GEM exerted concentrationdependent anti-tumor effects. The $\mathrm{IC}_{50}$ was $64.7 \mathrm{ng} / \mathrm{ml}$.

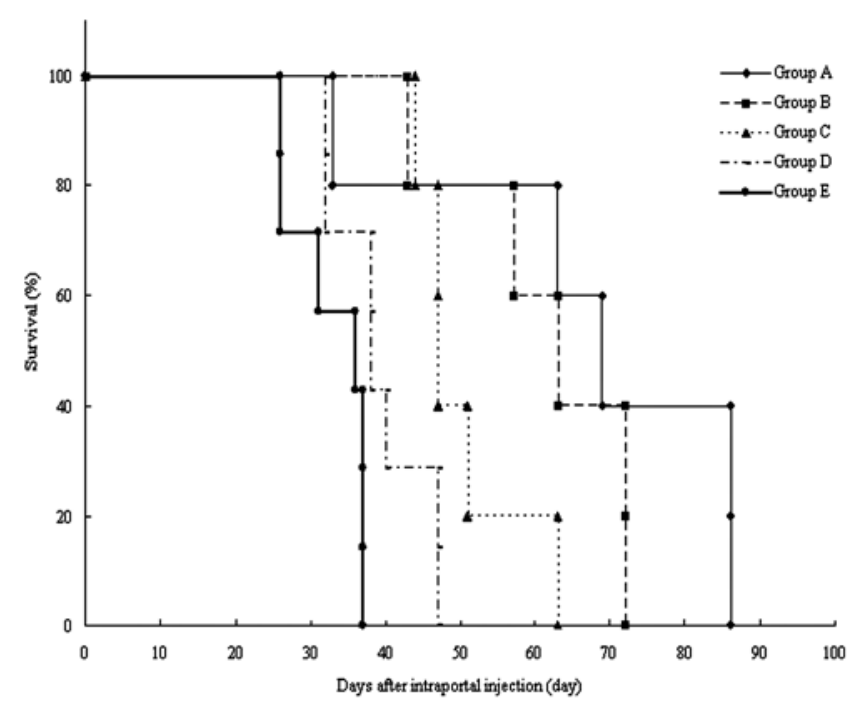

Figure 2. The number of tumor cells administered and cumulative survival period in models of liver metastasis using portal administration of PAN02. The survival rate 30 days after transplantation in Group A, B, C, or D was $100 \%$. The survival rate with Group $\mathrm{E}$ was $71.4 \%$. The survival rates 60 days after transplantation in Groups A, B, C, D and E were 80, 60, 20, 0 and 0\%, respectively. Group A, 5x10 cells $(n=5)$; Group B, $1 \times 10^{5}$ cells $(n=5)$; Group C, $2 \times 10^{5}$ cells $(n=5)$; Group D, $5 \times 10^{5}$ cells $(n=7)$; Group E, $1 \times 10^{6}$ cells $(n=7)$. which was punctured through the skin. IL-2 was dissolved in PBS, divided, and stored at $-80^{\circ} \mathrm{C}$ until use.

Experimental groups. Tumor-bearing mice were divided randomly into 4 groups for the experiment (Fig. 3). 1) In the control group $(n=10)$, no treatment was administered after tumor transplantation, and intraperitoneal administration of $0.1 \mathrm{ml}$ of PBS was started 7 days after the transplantation. The intraperitoneal administrations were performed every 2 days, 5 times in total. Ten days after the transplantation, intra-splenic administration of $10 \mu 1$ of PBS was started, and was performed for 10 consecutive days. 2) In the IL-2 group $(\mathrm{n}=10), 5,000 \mathrm{IU}$ of IL-2 were diluted with PBS, and the dose volume was set at $10 \mu 1$. Intra-splenic administration was started 10 days after transplantation, and was performed for 10 consecutive days. Seven days after transplantation, intraperitoneal administration of $0.1 \mathrm{ml}$ of PBS was started, and was performed every 2 days, 5 times in total. 3) In the GEM group $(\mathrm{n}=10), 80 \mathrm{mg} / \mathrm{kg}$ of GEM was diluted with PBS, and the dose volume was set at $0.1 \mathrm{ml}$. Intraperitoneal administration was started 7 days after transplantation, and was performed every 2 days, 5 times in total. Ten days after transplantation, intra-splenic administration of $10 \mu 1$ of PBS was started, and was performed for 10 consecutive days. 4) In the GEM+IL-2 group $(n=10)$, just as described above, intraperitoneal administration of GEM was started 7 days after transplantation, and was performed every 2 days, 5 times in total. Intra-splenic administration of IL-2 was started 10 days after transplantation, and was performed for 10 consecutive days. All mice were sacrificed 28 days after transplantation of PAN02 cells, and the number of metastases on the liver surface and the weight of the liver were determined in each group.

Collection of splenocytes and IFN- $\gamma$ production by splenocytederived (splenocytic) lymphocytes. Upon sacrifice, the spleen of each animal was excised, sliced thinly in PBS with scissors and ground with slide glass, and the splenocytes were isolated. After centrifugation at $1,500 \mathrm{rpm}$ (at $4^{\circ} \mathrm{C}$ for $5 \mathrm{~min}$ ), $1 \mathrm{ml}$ of lysis buffer $\left(150 \mathrm{mM} \mathrm{NH}_{4} \mathrm{Cl}, 14 \mathrm{mM} \mathrm{NaHCO}_{3}\right.$, and $0.1 \mathrm{mM}$ EDTA $1 \mathrm{Na}$ ) was added to initiate red cell lysis. After the mixture had been suspended for $10 \mathrm{~min}$, it was centrifuged for $10 \mathrm{~min}$ at 3,000 rpm, and splenocytic lymphocytes were

\section{$\begin{array}{llllll}\text { Day } 0 \quad \text { Day7 Day10 Day13 Day16 Day19 Day28 } & \text { Da }\end{array}$}

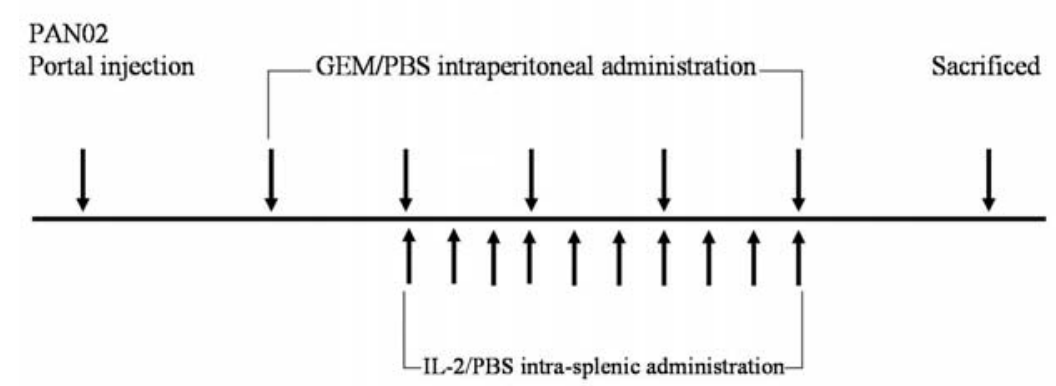

Figure 3. Experimental schedules. Models of liver metastasis were prepared by portal injection of $5 \times 10^{5}$ PAN02 cells. Intraperitoneal administration of gemcitabine (GEM; $80 \mathrm{mg} / \mathrm{kg}$ ) was started 7 days after tumor transplantation. GEM was administered every 2 days, 5 times in total. Splenic administration of IL-2 (5,000 IU/day) was started 10 days after tumor transplantation. IL-2 was administered for 10 consecutive days. The mice were sacrificed 28 days after transplantation of PAN02 cells. 
A

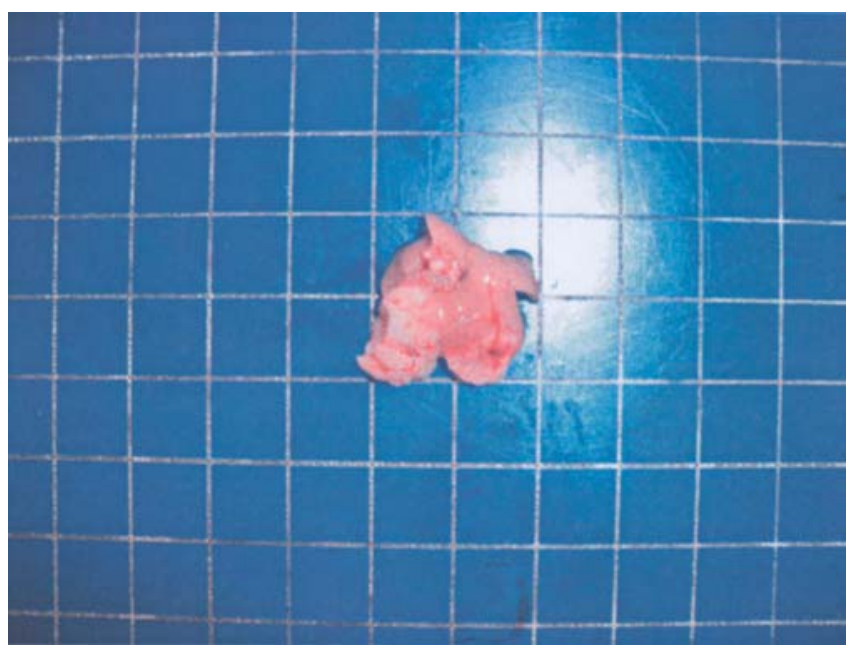

C

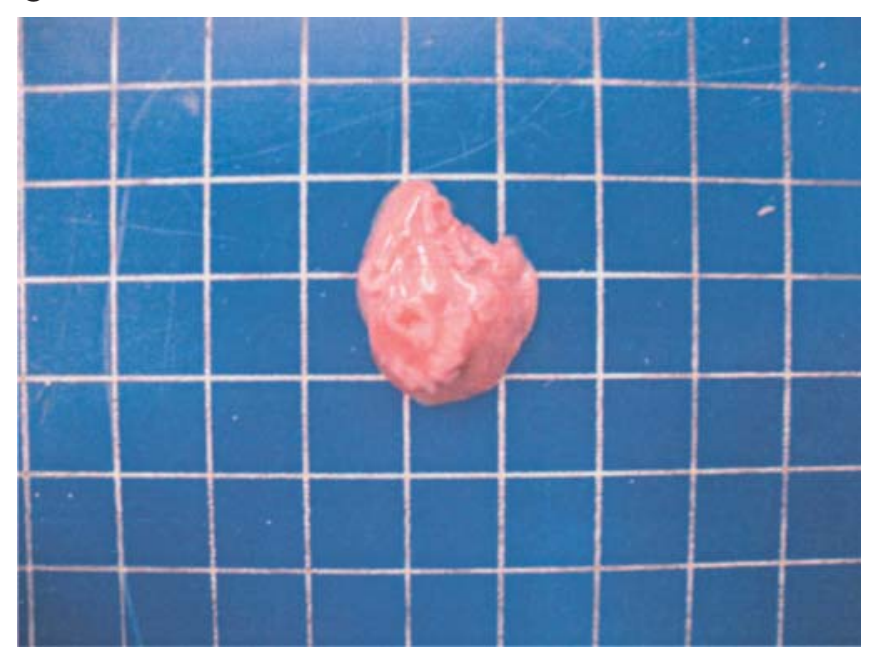

B

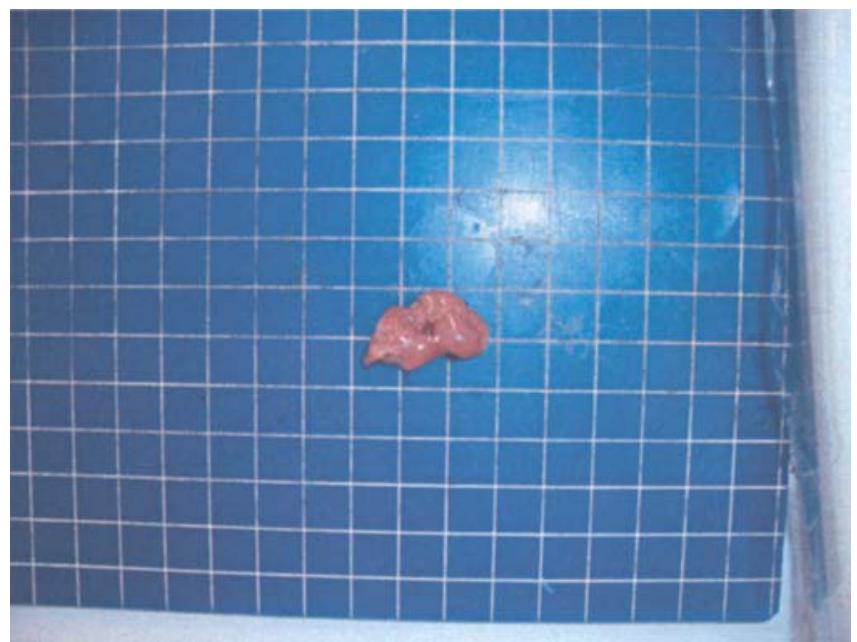

D

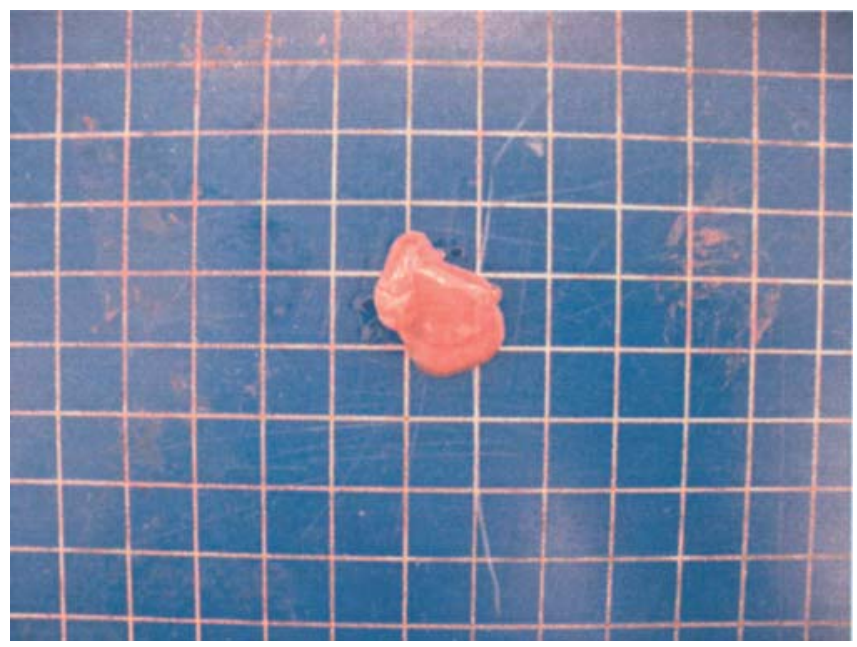

Figure 4. Findings of liver metastasis in each group. All mice were sacrificed 28 days after transplantation of PAN02 cells, and the liver was excised from each mouse. A, Control group; B, GEM group; C, IL-2 group; D, GEM+IL-2 group.

obtained. The concentration of splenocytic lymphocytes was adjusted to $3 \times 10^{6}$ cells $/ \mathrm{ml}$ in each group, and the cells were dispersed on a 24-well plate. After addition of $2.5 \mu \mathrm{g} / \mathrm{ml}$ of Concanavalin A (Con A) (Sigma) to the wells, the cells were incubated at $37^{\circ} \mathrm{C}$ for $48 \mathrm{~h}$ in an environment of $5 \% \mathrm{CO}_{2}$. The supernatant was collected and centrifuged at $9,000 \mathrm{rpm}$ (at $4^{\circ} \mathrm{C}$ for $5 \mathrm{~min}$ ), and the supernatant was then stored at $-80^{\circ} \mathrm{C}$. Subsequently, the concentration of IFN- $\gamma$ was measured with an enzyme-linked immunosorbent assay (ELISA) kit (Quantikine, R \& D Systems Inc., Minneapolis, MN, USA).

Histopathological assessment. Lung and liver tissues were excised, fixed in formalin, and embedded in paraffin for preparation of slices. The slides were stained with hematoxylineosin (HE) for the assessment of histopathology.

Winn assay. The murine pancreatic cancer cell strain PAN02 was used for target cells. The effector cells included splenocytes in the control group and the GEM+IL-2 group. The concentration of splenocytic cells was adjusted to $1.0 \times 10^{9}$ cells/ $\mathrm{ml}$ and suspended in PBS. Immediately before inoculation (transplantation) of the cells, $5 \times 10^{6}$ target $(\mathrm{T})$ cells per $0.1 \mathrm{ml}$ and $1 \times 10^{8}$ effector $(\mathrm{E})$ cells per $0.1 \mathrm{ml}$ were mixed, and a total of $0.2 \mathrm{ml}$ of the mixed cells at an E/T ratio of 20 was injected subcutaneously into the dorsum of each C57BL/6J mouse. After this subcutaneous inoculation, tumor timecourse changes in size were determined from the maximum diameter (long diameter) and the short diameter that crosses at right angles to the long diameter (Winn assay) (24). The tumor volume was calculated using the following formula after measurement of the short and long diameters of the tumor with micrometer calipers, according to the method by Attia and Weiss (25): [(short diameter $)^{2} \mathrm{x}$ long diameter] x 0.4 .

Statistical analysis. The data are expressed as mean \pm standard error (SE). Analysis of variance (ANOVA) and Student's t-test were used to test the significance of differences among the treatment groups. Differences at a risk rate of $<5 \%$ were considered significant.

\section{Results}

Anti-tumor effects of the combined use of GEM and IL-2 in models of liver metastasis of pancreatic cancer. The laparo- 


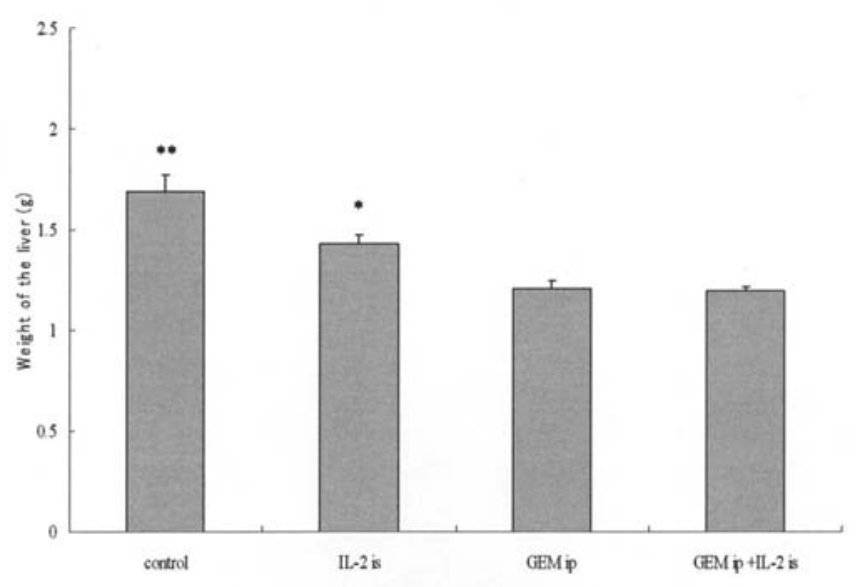

Figure 5. Anti-tumor effects of the combined use of GEM and IL-2 in models of liver metastasis of murine pancreatic cancer (PAN02) (weight of the liver). The anti-tumor effect was expressed as the weight (g) of the liver 28 days after transplantation in each group. Liver weight was significantly lower in the GEM+IL-2 group than in the control and IL-2 groups, but there was no significant difference between the GEM+IL-2 group and the GEM group. Data are expressed as mean $\pm \mathrm{SE}$, statistically significant $\left({ }^{*} \mathrm{p}<0.001\right.$, $\left.{ }^{* *} \mathrm{p}<0.0001\right)$ compared with GEM ip + IL-2 is group ( $\mathrm{n}=10$ /group). ip, intraperitoneal administration; is, intra-splenic administration.

tomy findings observed 28 days after transplantation of PAN02 cells showed liver metastasis in all of the mice of each group (Fig. 4). No lung metastasis or peritoneal dissemination was recognized in any group. First, the weight of the liver in murine models of liver metastasis of pancreatic cancer was investigated. The weight of the liver was $1.69 \pm 0.08 \mathrm{~g}$ in the control group, $1.43 \pm 0.05 \mathrm{~g}$ in the IL-2 group, $1.20 \pm 0.04 \mathrm{~g}$ in the GEM group [significantly less than in the control group $(\mathrm{p}<0.0001)]$, and $1.19 \pm 0.02 \mathrm{~g}$ in the GEM+IL-2 group [showing the greatest decrease and significantly less than in the control $(\mathrm{p}<0.0001)$ and IL-2 $(\mathrm{p}<0.001)$ groups] (Fig. 5). The number of liver metastases was $84.4 \pm 5.0$ in the control group, $35.4 \pm 3.9$ in the IL-2 group, and $29.7 \pm 3.1$ in the GEM group. Thus, the numbers in the IL-2 and GEM groups were decreased significantly compared with those in the control group. The number was $16.8 \pm 2.9$ in the GEM+IL-2 group, a significant decrease as compared with those in the control $(\mathrm{p}<0.0001)$, IL-2 $(\mathrm{p}<0.005)$ and GEM $(\mathrm{p}<0.01)$ groups (Fig. 6).

Comparison of the suppressive effects of intra-splenic (portal) administration and systemic administration of IL-2 on liver metastasis. At different times, the suppressive effect of systemic administration of IL-2 was compared with that of portal administration of IL-2 in the GEM+IL-2 group. The number of liver metastases was $3.3 \pm 0.8$ in the animals in which GEM had been administered and IL- 2 had been injected into the portal vein, while the number was $15 \pm 4.4$ in those receiving GEM and in which IL-2 had been administered systemically. Thus, the number was significantly $(\mathrm{p}<0.05)$ decreased in the former group of animals compared with that in the latter group (Fig. 7).

Assessment of suppressive effects according to IL-2 dose on liver metastasis. A 5,000-IU dose of IL-2 was compared with

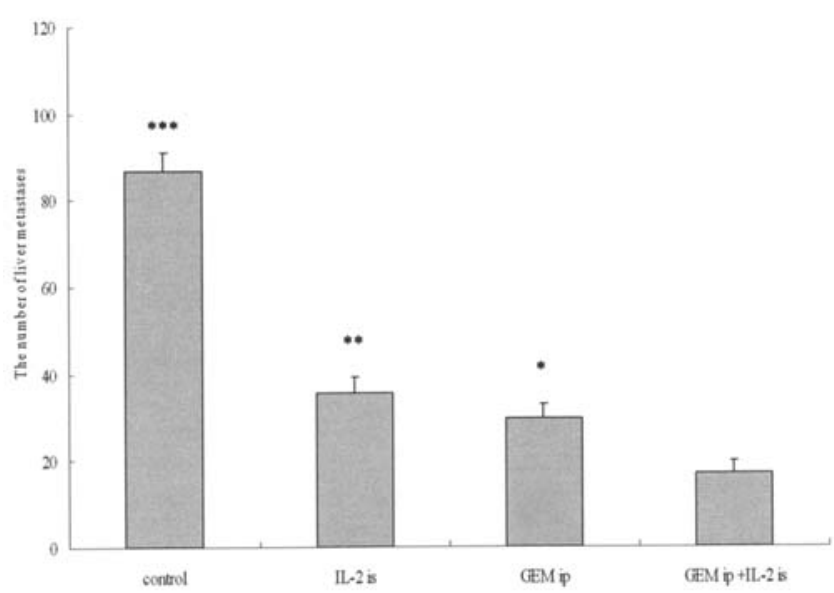

Figure 6. The anti-tumor effects of the combined use of GEM and IL-2 in models of liver metastasis of murine pancreatic cancer (PAN02) (the number of liver metastases). The anti-tumor effects were expressed as the number of liver metastases measured 28 days after transplantation in each group. The number was reduced significantly in the GEM+IL-2 group compared with all other groups. Data are expressed as mean \pm SE, statistically significant $\left({ }^{*} \mathrm{p}<0.01,{ }^{* *} \mathrm{p}<0.005,{ }^{* * *} \mathrm{p}<0.0001\right)$ compared with GEM+IL-2 group ( $\mathrm{n}=10 /$ group). ip, intraperitoneal administration; is, intra-splenic administration.

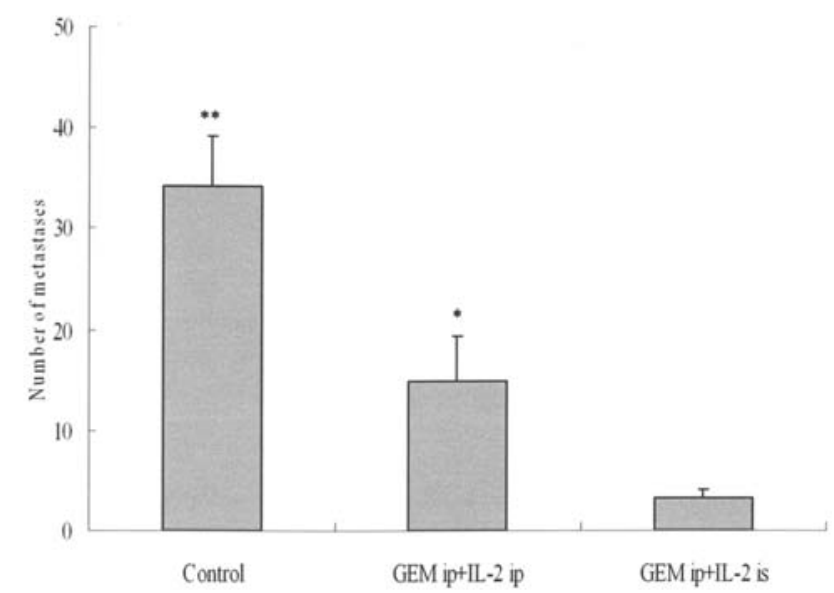

Figure 7. Comparison of the suppressive effects of IL-2 administered locally into the portal vein and IL-2 administered systemically on liver metastasis. The numbers of liver metastases were $3.3 \pm 0.8$ and $15 \pm 4.4$ in the GEM+IL-2 (administered portally) and the GEM+IL-2 (administered systemically) groups, respectively. The number was significantly reduced in the former compared with the latter group. Data are given as mean \pm SE, statistically significant $\left({ }^{*} \mathrm{p}<0.05,{ }^{* *} \mathrm{p}<0.0001\right)$ compared with GEM ip + IL-2 is group ( $\mathrm{n}=10 /$ group). ip, intraperitoneal administration; is, intra-splenic administration.

a dose of $10,000 \mathrm{IU}$ in terms of the degree of the suppressive effect on liver metastasis in the GEM+IL-2 group. When the dose was 5,000 IU, the number of liver metastases decreased to $20 \%$ of that in the control group, whereas the number decreased to $5 \%$ of that in the control group when the dose was raised to $10,000 \mathrm{IU}$ (Fig. 8).

In vitro cytocidal effects of the combined use of GEM and IL-2 on PANO2 cells. The MTT assay was used to determine whether the combined use of IL-2 and GEM exerts in vitro additive or synergistic cytocidal effects on PAN02 cells. As 


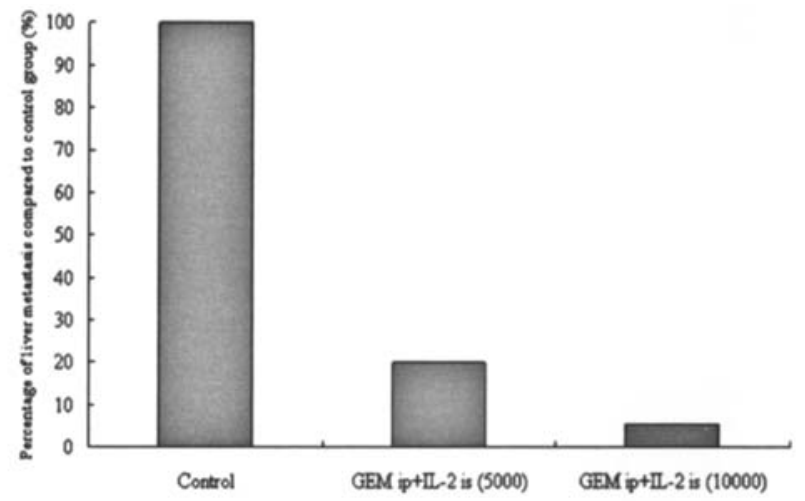

Figure 8. Assessment of suppressive effects according to IL-2 dose on liver metastasis. When the number of liver metastases in the control group was regarded as $100 \%$, the number was decreased to $20 \%$ at 5,000 IU of IL-2, and $5 \%$ at the dose raised to $10,000 \mathrm{IU}$ ( $\mathrm{n}=10$ /group).

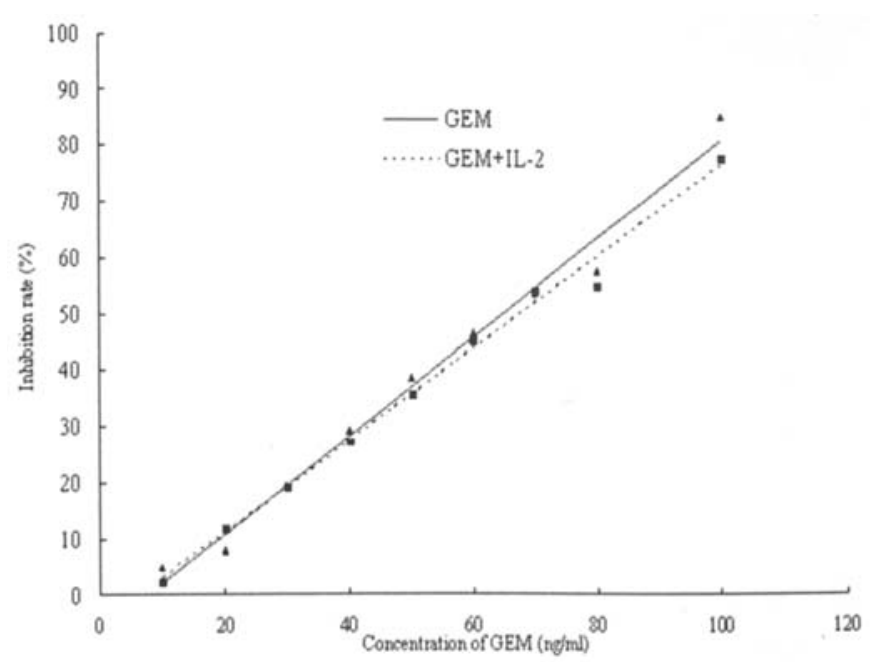

Figure 9. In vitro cytocidal effects of GEM and IL-2 on tumor cell strain PANO2 of murine pancreatic cancer (MTT assay). The cytocidal effects of the combined use of GEM and IL-2 on PAN02 were essentially the same as those of GEM alone. The $\mathrm{IC}_{50}$ with the combined use of IL-2 and GEM was $67.7 \mathrm{ng} / \mathrm{ml}$

described in Materials and methods, evaluation by MTT assay requires at most $72 \mathrm{~h}$. The cytocidal effects of combined use on PAN02 cells were quite similar to those seen with single-agent GEM, suggesting that IL-2 per se has no cytocidal effect on PAN02 cells and that IL-2 does not increase the anti-tumor effect of GEM (Fig. 9). The $\mathrm{IC}_{50}$ of GEM for PAN02 cells was $64.7 \mathrm{ng} / \mathrm{ml}$, and the $\mathrm{IC}_{50}$ for the combined use of GEM and IL-2 was $67.7 \mathrm{ng} / \mathrm{ml}$.

IFN- $\gamma$ production from splenocytic lymphocytes. The level of IFN- $\gamma$ produced after stimulation of Con $\mathrm{A}$ in splenocytic lymphocytes was $560.0 \pm 45.7 \mathrm{pg} / \mathrm{ml}$ in the GEM+IL-2 group, showing a remarkable increase. This was a significant $(\mathrm{p}<0.001)$ increase as compared to the levels of $230.7 \pm 26.8$, $240.3 \pm 21.8$, and $191.3 \pm 34.5 \mathrm{pg} / \mathrm{ml}$ in the control, GEM, and IL-2 groups, respectively (Fig. 10).

Histological assessment. Each group showed metastatic foci in the liver and poorly differentiated tubular adenocarcinoma,

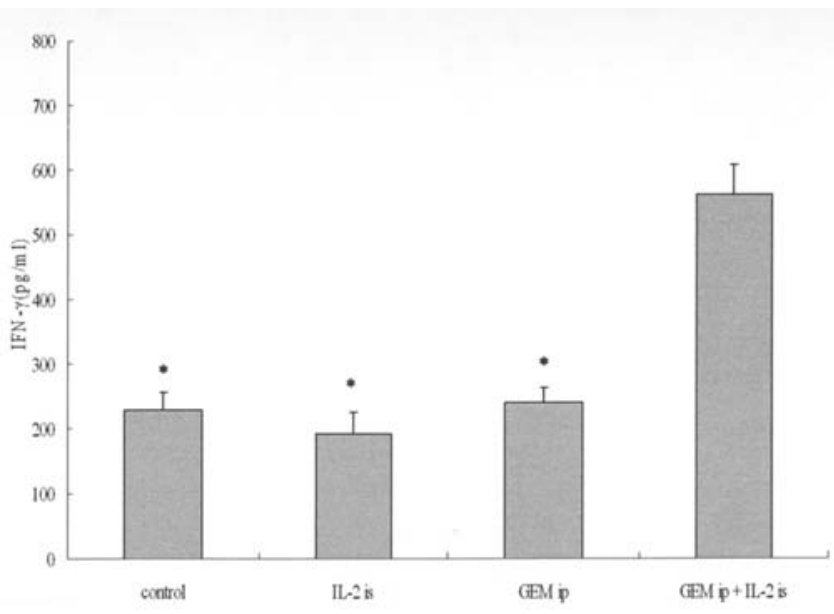

Figure 10. IFN- $\gamma$ production by splenocytic lymphocytes. Splenocytic lymphocytes in each group were incubated with Concanavalin A (Con A, $2.5 \mu \mathrm{g} / \mathrm{ml}, 48 \mathrm{~h}$ ), and the supernatant IFN- $\gamma$ level was measured. The level was significantly increased in the GEM+IL-2 group compared with all other groups. Data are given as mean $\pm \mathrm{SE}$, statistically significant $\left({ }^{*} \mathrm{p}<0.0001\right)$ compared with GEM ip + IL-2 is group. ip, intraperitoneal administration; is, intra-splenic administration.

while the GEM+IL-2 group showed more marked lymphocyte infiltration into the tumor than the control group, despite the presence of poorly differentiated tubular adenocarcinoma (Fig. 11). To investigate side-effects, pulmonary complications including pulmonary edema were assessed, but there were no findings of distinct hyperpermeability of capillary blood vessels, which would include intra-alveolar serous retention (data not shown).

Assessment of the anti-tumor activity of splenocytic lymphocytes by the Winn assay. To assess the presence of specific effector cells that exert anti-tumor effects on PAN02 cells with administration of GEM and IL-2, the anti-tumor effects of the combined use of these agents on murine splenocytic lymphocytes were investigated. The splenocytic lymphocytes collected 28 days after transplantation of murine PAN02 cells from the control and GEM+IL-2 groups were mixed with PAN02 cells, serving as target cells, at an E/T ratio of 20. The activity of the lymphocytes was then investigated using the Winn assay. The transplanted PAN02 cells showed incorporation into the host's tissues and growth in all cases. There was a significant difference in tumor size between the control group and the GEM+IL-2 group (p<0.005) (Fig. 12).

\section{Discussion}

We have herein established combined immuno-chemotherapy with systemically administered gemcitabine and intra-portal administration of IL-2, which effectively suppressed liver metastases of pancreatic cancer in a murine model. Most pancreatic cancers are unresectable and progressive when the diagnosis is made, because of difficulty in early detection. The prognosis of pancreatic cancer remains poor. Even in cases that are resectable, the liver metastases that frequently develop postoperatively have been regarded as one of the factors adversely influencing prognosis (26). Undetected preoperative foci of liver metastases or micro-carcinoma 
A

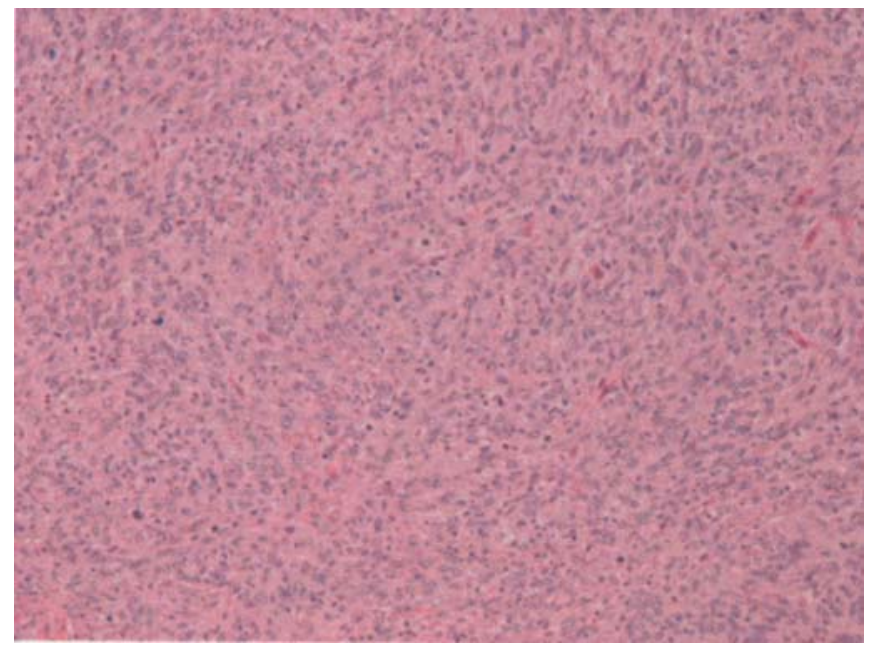

C

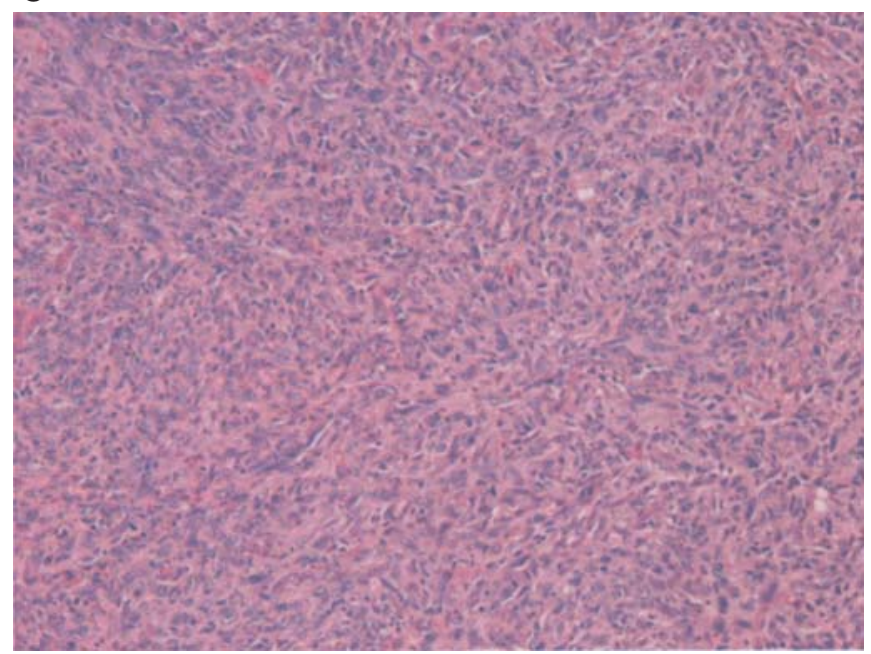

B

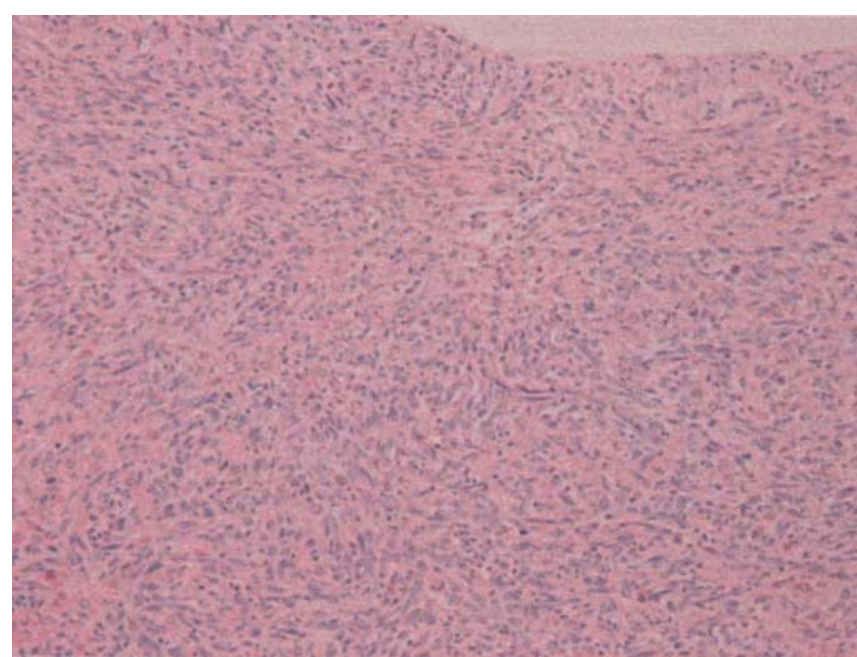

D

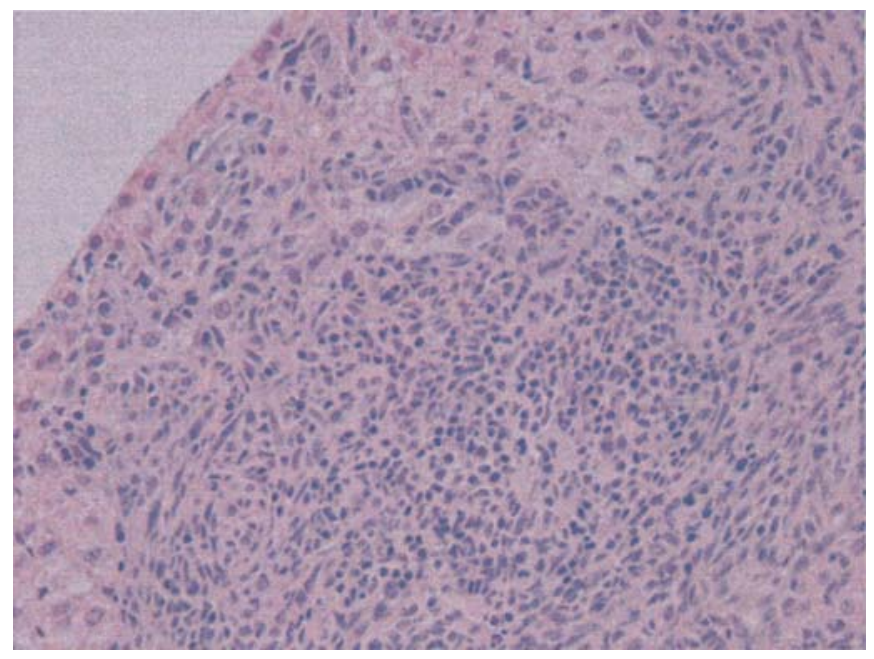

Figure 11. Histopathological findings in foci of liver metastases in each group (low magnification). A, Control group; B, GEM group; C, IL-2 group; D, GEM+IL-2 group. H\&E staining, x200.

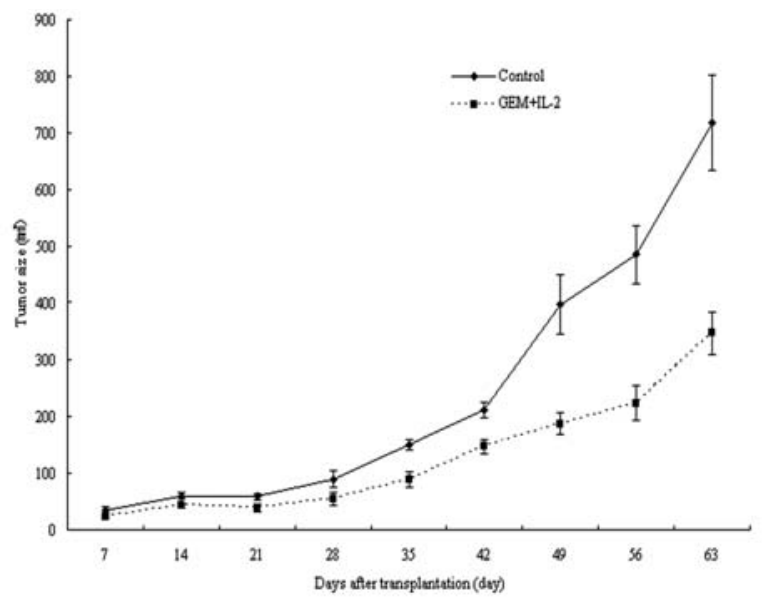

Figure 12. Anti-tumor effects of splenocytic lymphocytes by the Winn assay. Lymphocytes collected 28 days after transplantation of PAN02 cells in the control and GEM+IL-2 groups were regarded as effector (E) cells. PAN02 cells $\left(5 \times 10^{6}\right)$, regarded as target $(\mathrm{T})$ cells, were mixed with E cells at an $\mathrm{E} / \mathrm{T}$ ratio of 20 , and the resulting mixture was inoculated subcutaneously into the dorsal regions of $\mathrm{C} 57 \mathrm{BL} / 6 \mathrm{~J}$ mice. Time-course changes in the maximum diameter (long diameter) and that crossing at right angles to it (short diameter) were determined after subcutaneous inoculation (by the Winn assay). There was a significant difference in tumor size between the control group and the GEM+IL-2 group (ANOVA, p<0.005). cells dispersed mechanically by intraoperative procedures are the source of apparent metastatic foci, as they spread by taking advantage of the opportunity created by the decreased immunological competence of the host. Adjuvant therapy after surgical resection is absolutely required to reduce the recurrence of liver metastasis and to improve the prognosis of pancreatic cancer.

Some reports have suggested that in vivo progression of carcinoma growth leads to activation of deleterious immune responses, as manifested by immune complex formation, activation of suppressor $\mathrm{T}$ cells and macrophages, and helper $\mathrm{T}$ cell hypo-function, ultimately resulting in a collapse of the vital immunological surveillance mechanism (27-29). It is highly probable that, even though most of the tumor cells are surgically resected under such circumstances, remaining cancer cells will grow again in the tumor-bearing host itself, in which immunological competence is decreased postoperatively. Adoptive immunology therapy (AIT) using LAK cells has been employed as an adjunctive method of boosting host immune responses $(30,31)$. One report showed liver metastasis of sarcoma to be suppressed by AIT (32). Rosenberg et al (13), who administered IL-2 to 409 cancer patients (182 with melanoma and 227 with renal cell cancer), reported 
favorable therapeutic outcomes: complete response in 33 (12 and 21) and partial response in 37 (15 and 22). However, some reports have noted a high incidence of influenza-like symptoms with systemic administration, including pyrexia, chills, arthralgia, and nausea, and some cases had severe side-effects, i.e., capillary leak syndrome induced by intravascular hyperpermeability of IL-2 can result in remarkable systemic edema (due to retention of humoral fluid in the third space), pulmonary edema, hypotension, oliguria, and disturbance of consciousness, and may have a fatal course due to rapidly worsening circulatory insufficiency or respiratory failure (14-17). Furthermore, it is difficult for an adequate local concentration of systemically administered IL-2 to be maintained, which limits the anti-tumor effect. To solve these problems, IL-2 was administered into the portal vein for the purpose of increasing the local concentration, and the possibility of administration being more effective without inducing side-effects was considered $(33,34)$.

One of the causes of poor therapeutic outcomes in pancreatic cancer is the presence of postoperative liver metastasis in $62-92 \%$ of patients treated by radical operation (35-38). Effective adjuvant therapy, especially for prevention of liver metastasis, after the resection of pancreatic cancer has not been established (39-42). Our group has long investigated the effects of 5-FU administered via the portal vein; portal catheterization was performed before gastrointestinal reconstruction after the lesion of the pancreas had been resected intraoperatively, and 5-FU was administered serially through the portal catheter postoperatively (43). There was no significant difference in the incidence of local recurrence, but the incidence of liver metastasis of pancreatic cancer in the group treated postoperatively through the portal catheter was significantly lower than that in the group treated only with surgery. Nevertheless, the postoperative survival period in the group treated with the anticancer agent through the portal catheter was still limited. Activation of strong anti-tumor immunity by immunotherapy, in addition to the use of anticancer substances, may provide more effective anti-tumor therapy for postoperatively undetectable foci of liver metastasis of pancreatic cancer or micro-carcinoma cells dispersed mechanically by intraoperative procedures.

In the present study, the portal route was adopted based on the hypotheses that local immunocompetent cells in the liver would be activated and that their actions would be promoted by a high concentration of IL-2 administered directly via the portal system. In addition, this strategy was designed to reduce the side-effects of systemically administered IL-2, as described earlier. In our murine models of liver metastasis of pancreatic cancer, both the weight of the liver and the number of liver metastases were decreased significantly by systemic administration of GEM and intra-splenic (portal) administration of IL-2, as compared to those in the control group. The suppressive effect of this combination on liver metastasis was also significantly more favorable than that obtained with the use of either IL-2 or GEM alone. In addition, histopathological examination of the lungs in each group did not show any pulmonary edema, suggesting no systemic toxicity of IL-2. Thus, our results indicated that the simultaneous administration of an anticancer substance and an immune-activating cytokine could be an effective prophylactic countermeasure against liver metastasis of pancreatic cancer, with minimal side-effects.

GEM and IL-2 exerted no additive or synergistic effect in terms of in vitro cytocidal effects, raising the possibility that the in vivo effects are exerted via immunological functions of the murine host. This assumption is reasonable, given the fact that the infiltration of chronic inflammatory cells and lymphocytes in the liver metastatic foci was greater in the GEM+IL-2 group than in the control group.

The advent of GEM for the treatment of unresectable pancreatic cancer, a disease for which there have been few or no effective therapeutic methods, has been revolutionary (1). Like cytarabine (Ara-C), which has a structure similar to that of GEM, GEM is reportedly metabolized by a triphosphorylating substance (dFdCTP) after incorporation by cells, and is then incorporated into the DNA chain as a result of competition with deoxycytidine triphosphate (dCTP) to inhibit DNA and ultimately to induce apoptosis (12). Decreased host immunological competence is generally recognized as an adverse effect of administration of anticancer agents. The decreases in humoral immunity and cellular immunological competence enable opportunistic infection and have a major influence on the host's prognosis. Since the tumor-bearing host per se is in a hypo-immunocompetent state, it may be necessary to discontinue treatment because of further deterioration of immunological competence due to administration of anticancer agents (44). Therefore, innovations in the maintenance of host immunological competence appear to be needed. It has been reported that B-lymphocytes are selectively reduced by GEM administration, and $\mathrm{IgG}$ production in response to tumor antigens is significantly suppressed in the body (45). However, some reports have raised the possibility that GEM administration may increase the anti-tumor effects of tumor-specific CD4-positive T cells and CD8-positive T cells (45-47). In addition, this possibility was stated based on augmentation of cross-presentation of tumor antigens by antigen-presenting cells including dendritic cells. Tumor antigens are released by tumor cells in which apoptosis has been induced by GEM, leading to increased incorporation by antigen-presenting cells and activation of CD8-positive $\mathrm{T}$ cells that recognize the tumor antigen manifesting on MHC Class I. The cytotoxic activity of T cells was considered to be augmented and induction of differentiation of CTL to be promoted by IL-2 administered locally. Whether memory $\mathrm{T}$ cells that attained reactivity with splenocytic lymphocytes could be induced was assessed by the Winn assay. The tumor diameter was decreased significantly with splenocytic lymphocytes in the GEM+IL-2 group compared with the diameter in the control group. Furthermore, IFN- $\gamma$ production by splenocytic lymphocytes after stimulation of Con A was increased markedly in the GEM+IL-2 group as compared to other groups. These observations suggested that the cellular immunity would be improved as a result of the increase in IFN- $\gamma$ production and that memory $\mathrm{T}$ cells were induced, in part, with systemic GEM administration and portal IL-2 administration in models of liver metastasis of pancreatic cancer.

In conclusion, these findings suggested that, if combined with portal administration of IL-2, GEM may prevent liver metastasis of pancreatic cancer more effectively by increasing 
tumor antigen cross-presentation as well as by creating an environment in which $\mathrm{T}$ cells manifest their effects easily, while side-effects are minimized. Combined immunochemotherapy with GEM and IL-2 could be an effective clinical treatment for adjuvant therapy of pancreatic carcinoma after surgery.

\section{Acknowledgments}

We thank Mrs. Yuki Nakamura and Mr. Toshihide Muramatsu for their technical assistance. This work was supported in part by a Grant-in-Aid for Scientific Research (C) (15591359) from the Ministry of Education, Culture, Sports, Science and Technology, Japan.

\section{References}

1. Burris HA III, Moore MJ, Andersen J, Green MR, Rothenberg ML, Modiano MR, Cripps MC, Portenoy RK, Storniolo AM, Tarassoff P, Nelson R, Dorr FA, Stephens CD and von Hoff DD: Improvements in survival and clinical benefit with gemcitabine as first-line therapy for patients with advanced pancreas cancer: a randomized trial. J Clin Oncol 15: 2403-2413, 1997.

2. Berlin JD, Catalano P, Thomas JP, Kugler JW, Haller DG and Benson AB III: Phase III study of gemcitabine in combination with fluorouracil versus gemcitabine alone in patients with advanced pancreatic carcinoma: Eastern Cooperative Oncology Group Trial E2297. J Clin Oncol 20: 3270-3275, 2002.

3. Colucci G, Giuliani F, Gebbia V, Biglietto M, Rabitti P, Uomo G, Cigolari S, Testa A, Maiello E and Lopez M: Gemcitabine alone or with cisplatin for the treatment of patients with locally advanced and/or metastatic pancreatic carcinoma: a prospective, randomized phase III study of the Gruppo Oncologia dell'Italia Meridionale. Cancer 94: 902-910, 2002.

4. Okada S, Ueno H, Okusaka T, Ikeda M, Furuse J and Maru Y: Phase I trial of gemcitabine in patients with advanced pancreatic cancer. Jpn J Clin Oncol 31: 7-12, 2001.

5. Rocha Lima CM, Green MR, Rotche R, Miller WH Jr, Jeffrey GM, Cisar LA, Morganti A, Orlando N, Gruia G and Miller LL: Irinotecan plus gemcitabine results in no survival advantage compared with gemcitabine monotherapy in patients with locally advanced or metastatic pancreatic cancer despite increased tumor response rate. J Clin Oncol 22: 3776-3783, 2004.

6. Van Cutsem E, van de Velde H, Karasek P, Oettle H, Vervenne WL, Szawlowski A, Schoffski P, Post S, Verslype C, Neumann H, Safran H, Humblet Y, Perez Ruixo J, Ma Y and von Hoff D: Phase III trial of gemcitabine plus tipifarnib compared with gemcitabine plus placebo in advanced pancreatic cancer. J Clin Oncol 22: 1430-1438, 2004.

7. Oettle H, Richards D, Ramanathan RK, van Laethem JL, Peeters M, Fuchs M, Zimmermann A, John W, von Hoff D, Arning $\mathrm{M}$ and Kindler HL: A phase III trial of pemetrexed plus gemcitabine versus gemcitabine in patients with unresectable or metastatic pancreatic cancer. Ann Oncol 16: 1639-1645, 2005.

8. Bramhall SR, Schulz J, Nemunaitis J, Brown PD, Baillet M and Buckels JA: A double-blind placebo-controlled, randomised study comparing gemcitabine and marimastat with gemcitabine and placebo as first line therapy in patients with advanced pancreatic cancer. Br J Cancer 87: 161-167, 2002.

9. Oettle H, Post S, Neuhaus P, Gellert K, Langrehr J, Ridwelski K, Schramm H, Fahlke J, Zuelke C, Burkart C, Gutberlet K, Kettner E, Schmalenberg H, Weigang-Koehler K, Bechstein WO, Niedergethmann M, Schmidt-Wolf I, Roll L, Doerken B and Riess H: Adjuvant chemotherapy with gemcitabine vs observation in patients undergoing curative-intent resection of pancreatic cancer: a randomized controlled trial. JAMA 297: 267-277, 2007.

10. Sakon M, Nagano H, Dono K, Nakamori S, Umeshita K, Yamada A, Kawata S, Imai Y, Iijima S and Monden M: Combined intraarterial 5-fluorouracil and subcutaneous interferonalpha therapy for advanced hepatocellular carcinoma with tumor thrombi in the major portal branches. Cancer 94: 435-442, 2002.
11. Okuno K, Yasutomi M, Kon M, Hatakeyama K, Muto T, Kitajima M, Koyanagi Y, Hamano K, Ohta H, Aiba K, Arai Y, Sowa M, Kikkawa N, Takayasu $\mathrm{Y}$ and Isomoto $\mathrm{H}$ : Intrahepatic interleukin-2 with chemotherapy for unresectable liver metastases: a randomized multicenter trial. Hepatogastroenterology 46: 1116-1121, 1999.

12. Huang $P$ and Plunkett $W$ : Induction of apoptosis by gemcitabine. Semin Oncol 22: 19-25, 1995.

13. Rosenberg SA, Yang JC, White DE and Steinberg SM: Durability of complete responses in patients with metastatic cancer treated with high-dose interleukin-2: identification of the antigens mediating response. Ann Surg 228: 307-319, 1998.

14. Atkins MB, Sparano J, Fisher RI, Weiss GR, Margolin KA, Fink KI, Rubinstein L, Louie A, Mier JW, Gucalp R, Sosman JA, Boldt DH, Doroshow JH, Aronson FR and Sznol M: Randomized phase II trial of high-dose interleukin-2 either alone or in combination with interferon alfa- $2 b$ in advanced renal cell carcinoma. J Clin Oncol 11: 661-670, 1993.

15. Jones M, Philip T, Palmer P, von der Maase H, Vinke J, Elson P, Franks CR and Selby P: The impact of interleukin-2 on survival in renal cancer: a multivariate analysis. Cancer Biother 8: 275-288, 1993.

16. Law TM, Motzer RJ, Mazumdar M, Sell KW, Walther PJ, O'Connell M, Khan A, Vlamis V, Vogelzang NJ and Bajorin DF: Phase III randomized trial of interleukin-2 with or without lymphokine-activated killer cells in the treatment of patients with advanced renal cell carcinoma. Cancer 76: 824-832, 1995.

17. Quan WD Jr, Khan N, Ramirez M, Taylor WC, Quan F, Vinogradov M and Walker P: Correlation between development of pulmonary edema and response of pulmonary metastases of metastatic melanoma and kidney cancer to high-dose continuousinfusion interleukin-2. Cancer Biother Radiopharm 20: 151-154, 2005.

18. Mackay IR: Hepatoimmunology: a perspective. Immunol Cell Biol 80: 36-44, 2002.

19. Shimoyama Y, Kubota T, Watanabe M, Ishibiki K and Abe O: Predictability of in vivo chemosensitivity by in vitro MTT assay with reference to the clonogenic assay. J Surg Oncol 41: 12-18, 1989.

20. Suto A, Kubota T, Shimoyama Y, Ishibiki K and Abe O: MTT assay with reference to the clinical effect of chemotherapy. J Surg Oncol 42: 28-32, 1989.

21. Furukawa T, Kubota T, Suto A, Takahara T, Yamaguchi H, Takeuchi T, Kase S, Kodaira S, Ishibiki K and Kitajima M: Clinical usefulness of chemosensitivity testing using the MTT assay. J Surg Oncol 48: 188-193, 1991.

22. Mosmann T: Rapid colorimetric assay for cellular growth and survival: application to proliferation and cytotoxicity assays. J Immunol Methods 65: 55-63, 1983.

23. Su W, Kitagawa T, Ito T, Oyama T, Lee CM, Kim YK and Matsuda H: Antitumor effect to IL-12 administration into the portal vein on murine liver metastasis. J Hepatobiliary Pancreat Surg 9: 503-510, 2002.

24. Winn HJ: The immune response and the homograft reaction. Natl Cancer Inst Monogr 2: 113-138, 1960.

25. Attia MA and Weiss DW: Immunology of spontaneous mammary carcinomas in mice. V. Acquired tumor resistance and enhancement in strain A mice infected with mammary tumor virus. Cancer Res 26: 1787-1800, 1966.

26. Beger HG, Rau B, Gansauge F, Poch B and Link KH: Treatment of pancreatic cancer: challenge of the facts. World J Surg 27: 1075-1084, 2003.

27. Fujimoto S, Greene MI and Sehon AH: Regualtion of the immune response to tumor antigens. I. Immunosuppressor cells in tumorbearing hosts. J Immunol 116: 791-799, 1976.

28. Shibata Y, Shibuya E and Ishida N: Relationships between suppressor macrophages and macrophage precursors in the spleens from tumor-bearing mice. Cell Immunol 85: 45-57, 1984.

29. Burger CJ, Elgert KD and Farrar WL: Interleukin 2 (IL-2) activity during tumor growth: IL-2 production kinetics, absorption of and responses to exogenous IL-2. Cell Immunol 84: 228-239, 1984

30. Rosenberg SA: Adoptive immunotherapy of cancer: accomplishments and prospects. Cancer Treat Rep 68: 233-255, 1984.

31. Rosenberg SA: The adoptive immunotherapy of cancer using the transfer of activated lymphoid cells and interleukin-2. Semin Oncol 13: 200-206, 1986.

32. Lafreniere R and Rosenberg SA: Successful immunotherapy of murine experimental hepatic metastases with lymphokineactivated killer cells and recombinant interleukin 2. Cancer Res 45: 3735-3741, 1985. 
33. Tanji H, Yahata H, Hayamizu K, Shinozaki K, Okimoto T, Sakaguchi $\mathrm{T}$ and Asahara T: Augmentation of local antitumor immunity in liver by interleukin-2 gene transfer via portal vein. Cancer Gene Ther 9: 655-664, 2002.

34. Toloza EM, Hunt K, Swisher S, McBride W, Lau R, Pang S, Rhoades K, Drake T, Belldegrun A, Glaspy J and Economou JS: In vivo cancer gene therapy with a recombinant interleukin-2 adenovirus vector. Cancer Gene Ther 3: 11-17, 1996.

35. Sperti C, Pasquali C, Piccoli A and Pedrazzoli S: Recurrence after resection for ductal adenocarcinoma of the pancreas. World J Surg 21: 195-200, 1997.

36. Kayahara M, Nagakawa T, Ueno K, Ohta T, Takeda $\mathrm{T}$ and Miyazaki I: An evaluation of radical resection for pancreatic cancer based on the mode of recurrence as determined by autopsy and diagnostic imaging. Cancer 72: 2118-2123, 1993.

37. Westerdahl J, Andren-Sandberg A and Ihse I: Recurrence of exocrine pancreatic cancer-local or hepatic? Hepatogastroenterology 40: 384-387, 1993.

38. Takahashi S, Ogata Y, Miyazaki H, Maeda D, Murai S, Yamataka K and Tsuzuki T: Aggressive surgery for pancreatic duct cell cancer: feasibility, validity, limitations. World J Surg 19: 653-660, 1995

39. Smeenk HG, Incrocci L, Kazemier G, van Dekken H, Tran KT, Jeekel J and van Eijck CH: Adjuvant 5-FU-based chemoradiotherapy for patients undergoing R-1/R-2 resections for pancreatic cancer. Dig Surg 22: 321-328, 2005.

40. Neoptolemos JP, Dunn JA, Stocken DD, Almond J, Link K, Beger H, Bassi C, Falconi M, Pederzoli P, Dervenis C, Fernandez-Cruz L, Lacaine F, Pap A, Spooner D, Kerr DJ, Friess H, Büchler MW and for the members of the European Study Group for Pancreatic Cancer: Adjuvant chemoradiotherapy and chemotherapy in resectable pancreatic cancer: a randomised controlled trial. Lancet 358: 1576-1585, 2001.
41. Klinkenbijl JH, Jeekel J, Sahmoud T, van Pel R, Couvreur ML, Veenhof CH, Arnaud JP, Gonzalez DG, De Wit LT, Hennipman A and Wils J: Adjuvant radiotherapy and 5-fluorouracil after curative resection of cancer of the pancreas and periampullary region: phase III trial of the EORTC gastrointestinal tract cancer cooperative group. Ann Surg 230: 776-782, 1999.

42. Study Group of Surgical Adjuvant Therapy for Carcinomas of the Pancreas and Biliary Tract, Takada T, Amano H, Yasuda H, Nimura Y, Matsushiro T, Kato H, Nagakawa T and Nakayama T: Study Group of Surgical Adjuvant Therapy for Carcinomas of the Pancreas and Biliary Tract: is postoperative adjuvant chemotherapy useful for gallbladder carcinoma? A phase III multicenter prospective randomized controlled trial in patients with resected pancreaticobiliary carcinoma. Cancer 95: 1685-1695, 2002.

43. Takahashi S, Aiura K, Saitoh J, Hayatsu S, Kitajima M and Ogata Y: Treatment strategy for pancreatic head cancer: pyloruspreserving pancreatoduodenectomy, intraoperative radiotherapy and portal catheterization. Digestion 60: 130-134, 1999.

44. Laursen ML: Chemotherapy of malignant tumors - a selfdefeating form of immunotherapy? Med Hypotheses 29: 9-15, 1989.

45. Nowak AK, Robinson BW and Lake RA: Gemcitabine exerts a selective effect on the humoral immune response: implications for combination chemo-immunotherapy. Cancer Res 62: 2353-2358, 2002

46. Nowak AK, Robinson BW and Lake RA: Synergy between chemotherapy and immunotherapy in the treatment of established murine solid tumors. Cancer Res 63: 4490-4496, 2003.

47. Nowak AK, Lake RA, Marzo AL, Scott B, Heath WR, Collins EJ, Frelinger JA and Robinson BW: Induction of tumor cell apoptosis in vivo increases tumor antigen cross-presentation, cross-priming rather than cross-tolerizing host tumor-specific CD8 T cells. J Immunol 170: 4905-4913, 2003. 